\title{
Utrecht, 1713. Una paz posible para Europa ${ }^{1}$
}

\author{
Virginia LEÓN SANZ \\ Universidad Complutense de Madrid \\ virgleon@ucm.es
}

\section{RESUMEN}

Los Tratados de Utrecht ponían fin a la guerra de Sucesión española, un conflicto que ha sido objeto de un intenso debate historiográfico en los últimos años. La Paz de Utrecht es ahora analizada desde diversas ópticas de aproximación. Durante las negociaciones, Felipe V quiso imponer sus condiciones, pero finalmente debió aceptar lo acordado por Luis XIV con las potencias marítimas. El monarca borbónico tuvo que renunciar al trono francés, algo que nunca admitió realmente, y perdió los territorios europeos extrapeninsulares, pero mantuvo su imperio en América, debiéndose destacar el interés creciente de la historiografía sobre el contenido de los Tratados con relación al comercio colonial. Se analiza también la posición de Carlos VI, el rival al trono español, quien afrontó las negociaciones de la paz desde una aparente posición de fuerza, aunque se guió en la etapa final de la guerra por intereses contradictorios en la firme defensa de sus dos escenarios principales: Cataluña e Italia. La hegemonía de los Austrias de Madrid en Italia pasaba en Utrecht-Rastatt a los Austrias de Viena y su nuevo dominio era interpretado en clave de continuidad. Considerado como uno de los grandes proyectos europeos encaminados a salvaguardar la paz, Utrecht no consiguió hacer olvidar un conflicto que permanece cercano en la memoria.

Palabras clave: Paz de Utrecht, Guerra de Sucesión española, Felipe V, Carlos VI, negociaciones, Italia.

\section{Utrecht, 1713. A Peace possible for Europe}

\begin{abstract}
The Treaties of Utrecht ended the War of the Spanish Succession, a conflict that in recent years has been the subject of intense historical debate. The Peace of Utrecht is now analyzed from different perspectives. During negotiations, Philip V of Spain tried to impose their conditions, but eventually he had to accept the agreement of Louis XIV of France with the Maritime powers. The Spanish king had to renounce to the French throne-something h e never really admitted-, and lost his Spanish territories in Europe. He kept instead the Empire in America, being the content of the Treaties regarding colonial trade the subject of a growing historiographical interest. This contribution analyzes also the position of Charles VI of Austria, who claimed the Spanish throne and faced the peace negotiations from a position of apparent strength -although in the final stage of the war he was guided by conflicting interests regarding the rigid defense of his two main scenarios: Catalonia and Italy. In Utrecht-Rastatt, Spanish Habsburg hegemony in Italy was transferred to the Habsburgs of Vienna and this new domain was interpreted in terms of continuity. The Peace of Utrecht is considered a major European peacekeeping project, but it failed to forget a conflict that still remains close in memory.
\end{abstract}

Key words: Peace of Utrecht, War of the Spanish Succession, Philip V of Spain, Charles VI of Austria, negotiations, Italy.

1 Este número de Cuadernos de Historia Moderna. Anejos ha sido coordinado en el marco del proyecto del MINECO HAR2010-16941: Los Estados europeos después de la Paz de Utrecht: la pugna mediterránea (1713-1748), así como la realización del presente trabajo. 
Project pour render la Paix perpétuelle en Euorope, Utrech, $1713^{2}$. Con este título, el Abad de Saint Pierre publicaba una conocida obra sobre los Tratados que ponían fin a la guerra de Sucesión española. La ciudad holandesa de Utrecht acogió a los negociadores de la paz en enero de 1712 y quince meses después, el 30 de abril de 1713, se firmaba la primera serie de Tratados entre Francia y los países de la Alianza. El presente volumen pretende contribuir al interés despertado por la Paz de Utrecht con motivo de su tercer centenario. Un centenario que se conmemora con más éxito que los otros anteriores. La Europa de Utrecht tiene hoy una particular actualidad, en medio del debate sobre la construcción europea, al que no es ajeno la crisis politica y económica, necesitada de recuperar un espíritu de identidad y de unión como el imaginado por el Abad de Saint Pierre. Pero se trata también de una conmemoración que ha generado expectativas en el propio Estado español, por las consecuencias que se derivaron de la dimensión civil del conflicto sucesorio, con la disolución de la Corona de Aragón como conjunto orgánico y la desarticulación de la monarquía con la pérdida de territorios impuesta en los Tratados. Considerada como uno de los grandes proyectos europeos encaminados a salvaguardar la paz, Utrecht no consiguió hacer olvidar un conflicto que permanece cercano en la memoria ${ }^{3}$. Sin duda, nos hallamos en un momento de reflexión sobre los resultados de una paz concluida hace trescientos años.

\section{LA GUERRA DE SUCESIÓN ESPAÑOLA: UN CONFLICTO INTERNACIONAL Y UNA CONTIENDA CIVIL}

Desde el año 2000 se suceden los hitos conmemorativos relacionados con el cambio dinástico de Austrias a Borbones en España. El interés suscitado con motivo de la instauración de los Borbones con Felipe $\mathrm{V}$ y el conflicto internacional e interno que se desencadenó poco después ha sido objeto de intenso debate, lo que se ha plasmado en numerosas publicaciones, reuniones científicas y exposiciones, que han diversificado y multiplicado la óptica de aproximación a los acontecimientos iniciados en $1700^{4}$. Coincidente con otras conmemoraciones como la Guerra de Independencia, la Constitución de Cádiz, o Fernando el Católico, la Guerra de Sucesión española ha encontrado su propio espacio ${ }^{5}$. Han sido años prolíficos para repensar sobre el conflicto

\footnotetext{
2 SAINT PIERRE, Abad de: Project pour render la Paix perpétuelle en Euorope, Utrecht, 1713.

3 García CÁrcel, R.: Felipe Vy los españoles, Madrid, Plaza \& Janés, 2002; La herencia del pasado. Las memorias históricas de España, Barcelona, Galaxia Gutemberg, 2011.

4 Ribot García, L., A.: Orígenes políticos del testamento de Carlos II. La gestación del cambio dinástico en España. Madrid, Closas-Orcoyen, 2010; Kamen, H.: Felipe V. El rey que reinó dos veces. Madrid, Temas de hoy, 2000; Martínez Shaw, C., Alfonso, M.: Felipe V, Madrid, Arlanza Ediciones, 2001.

5 En España y en Europa contamos con diferentes eventos, exposiciones, seminarios y congresos así como publicaciones en torno a la Paz de Utrecht. Aunque impulsadas desde medios académicos, algunas de estas iniciativas cuentan con apoyos institucionales. A modo de ejemplo, cabe citar la exposición organizada en la ciudad de Utrecht (In Vredesnaam. De Vrede van Utrecht 1713), que llegará a la Fundación Carlos de Amberes a finales de año (En nombre de la Paz. La guerra de Sucesión española y los Tratados de Madrid, Utrecht, Rastatt y Baden 1713-1715, Diciembre de 2013-febrero 2014). Algunas reuniones científicas que se han celebrado ya, o lo harán en el transcurso del año, se configuran como una plataforma en la que especialistas y profesores universitarios presentan al debate académico sus investigaciones más relevantes. Cabe mencionar
} 
dinástico español, en los que las aportaciones realizadas han sido fundamentales para recuperar un período complejo y conflictivo ${ }^{6}$.

En estos años, la historiografía ha incidido en los diversos planos de la guerra de Sucesión en su doble vertiente de contienda internacional y de conflicto civil. La dimensión internacional de la contienda, en ocasiones relegada a un segundo lugar, ha ganado terreno y es analizada a partir de los intereses que implicaron a los diferentes países europeos, con especial atención a la posición de Francia e Inglaterra y su calculado apoyo a los dos rivales por el trono español, Felipe V y el Archiduque Carlos. Aunque la Monarquía ya no era el Estado más poderoso de Europa, seguía siendo el más extenso territorialmente y disfrutaba aún de enormes recursos y de formidables mercados, lo que acabó convirtiéndose, como señalara R.A. Stradling, en la verdadera sucesión española ${ }^{7}$. Fue una guerra dinástica, pero también un conflicto en el que se debatía el dominio marítimo y colonial, en el que estaban interesadas las potencias marítimas, Inglaterra y Holanda. Por eso, si el emperador Leopoldo reclamó sus derechos dinásticos a la muerte de Carlos II, las potencias marítimas entraron en el conflicto para evitar que la presencia de un Borbón en Madrid pudiera favorecer a los franceses en el comercio colonial español y en 1701, tras la cesión de Felipe V

entre otros Congresos Internacionales el Coloquio Internacional "Une paix pour l'Europe et le monde. Utrecht, 1713", que organiza el grupo Diplomatie et Paix de l'Université Paris-Sorbonne, junto al Centre Roland Mousnier EII, CLÉA (Sorbonne), de la dirección de los Archives du ministère des Affaires étrangères et européennes y el Institut Jaume Vicens i Vives de la Universitat Pompeu Fabra (Barcelona), en Paris y en La Courneuve (octubre 2013); entre los organizados en España, a modo de ejemplo, "Los hilos de Penélope, lealtad y fidelidades en la Monarquía de España, 1648-1715" (marzo de 2013), en la Universidad Autónoma de Madrid; "Tiempos de Utrecht, tiempos de cambio" (abril de 2013), en la Universidad Complutense de Madrid; V Seminario de Investigación de Historia Moderna (SIHMO) de la Universidad de Cantabria: "Europa en torno a Utrecht" (octubre-diciembre 2013); también el VII Congrés d'Història Moderna de Catalunya de la Universitat de Barcelona está dedicado a este tema: "Catalunya, entre la guerra i la pau: 1713, 1813" (diciembre 2013); así como la sección que dedicó el prestigioso XIX Congreso de Historia de la Corona de Aragón, celebrado en Zaragoza (junio de 2012). Asimismo, son reseñables las distintas miradas proporcionadas por distintos grupos como la RED SUCESIÓN, constituida por proyectos financiados por el MINECO, una Red de la que forma parte el proyecto en el marco del cual se ha coordinado este volumen.

6 La producción sobre la guerra de Sucesión ha sido muy numerosa y su incorporación en estas páginas sería una tarea muy compleja. Por este motivo, solo se ha pretendido fundamentar algunas ideas. Entre otras obras colectivas, algunas elaboradas a partir de Congresos y Seminarios, cabe citar como ejemplo: FeRNÁnDEZ Albadalejo, P. (ed.): Los Borbones. Dinastía y memoria de nación en la España del siglo XVIII, Madrid, Marcial Pons, 2000; Serrano, E.: Felipe V y su tiempo, Zaragoza, Institución Fernando el Católico, 2004; Cisneros, M., Morales, M., Renom, M. (eds.): L'aposta catalana a la Guerra de Successió, (1705-1707), Barcelona, Museu d'Història de Catalunya, 2007; Álvarez-Ossorio, A., García García, B., León Sanz, V. (coords.): La pérdida de Europa. La Guerra de Sucesión por la Monarquía de España, Madrid, Fundación Carlos de Amberes, 2007; García GonzÁlez, F. (coord.): La Guerra de Sucesión en España y la batalla de Almansa, Madrid, Sílex, 2007; Edelmayer, F., León Sanz, V., Ruiz Rodríguez, J. I. (eds.): Hispania-Austria III. Der Spanische Erbfolgekrieg - La Guerra de Sucesión española, Viena-Munich, Böhlau Verlag- Oldenbourg Wissenschaftsverlag, 2008; Bernardo Ares, J.M. (coord.): La sucesión de la Monarquía Hispánica, 16651725. Biografias relevantes y procesos complejos, SILEX Universidad (Madrid), Córdoba, 2009; GuASTI, N., Russo, S. (coords.): Il Viceregno austriaco, Roma, Carocci editore, 2010; Martínez Millán, J., Camarero Bullón, C., Luzzi, M. (coords): La Corte de los Borbones: Crisis del modelo cortesano, Colección Temas 8, I, Madrid, Editorial Polifemo, 2013. Asimismo, estos años han estado jalonados por dossiers de revistas científicas y de divulgación dedicadas a la guerra de Sucesión.

7 StRAdLing, R. A.: Europa y el declive de la estructura imperial española. 1580-1720, Madrid, Cátedra, 1992; edic. orig. 1981. Stein, S., Stein, B. H.: Plata, comercio y guerra. España y América en la formación de la Europa moderna, Barcelona, Crítica, 2000. 
del asiento a la Compañía de Guinea francesa, se formó la Gran Alianza de La Haya. También detrás de los vaivenes de la diplomacia portuguesa, de la neutralidad a la alianza primero con los Borbones y luego con los aliados, emerge la importancia de sus dominios ultramarinos y su necesaria defensa ${ }^{8}$.

La decisión relativa a la cesión del asiento se sumaba a otros desafíos de Luis XIV, como el establecimiento de tropas francesas en las plazas españolas de la barrera en Flandes o el reconocimiento de Jacobo III Estuardo como rey de Inglaterra y de los derechos del nuevo rey español al trono francés registrados en el Parlamento de París. Se debatía la hegemonía a escala mundial, pero también la hegemonía continental. La guerra de Sucesión dio lugar a la última gran coalición contra Luis XIV. En el centro del debate por la hegemonía europea se sitúa la rivalidad entre los Habsburgo y los Borbones. El candidato austriaco, convertido en emperador antes de finalizar la guerra, lidera la hegemonía de los Habsburgo, ahora de Viena, frente a la Casa de Borbón francesa y española. Los dominios italianos de la Monarquía, base de la hegemonía de la Monarquía Hispánica de los Austrias de Madrid, pasarán en Utrecht-Rastatt a los Austrias de Viena.

Por otro lado, los intereses dinásticos no sólo afectaron a la disputa de las Casas de Borbón y de Habsburgo al trono de España. En el seno de la Alianza, en la Corte de Viena se producen las renuncias del emperador Leopoldo y el archiduque José en 1703 a favor del archiduque Carlos, con el fin de asegurar la separación de Madrid y Viena; en estos acuerdos se encuentra el origen de la Pragmática sanción y la guerra de Sucesión austriaca. Por su parte, Inglaterra defendía el reconocimiento dinástico en la Casa de Hannover en el trono británico, tras el reinado de la reina Ana Estuardo. La cuestión dinástica se complicó en los momentos finales de la guerra. Si la muerte del emperador José cambió la posición de la Alianza con relación al candidato austriaco al trono de España, nuevo emperador Carlos VI, la diplomacia inglesa exigiría igualmente la renuncia de Felipe $\mathrm{V}$ al trono de Francia, tras la muerte del Delfín. Cuestiones dinásticas, intereses territoriales y coloniales, intereses económicos y comerciales, elecciones estratégicas: un juego que contextualiza la política de equilibrio ${ }^{9}$.

El factor internacional fue, pues, determinante en el origen, el desarrollo y desenlace de la guerra de Sucesión española. El dominio austriaco y aliado en Europa, tras los momentos iniciales, supuso la pérdida para Felipe V de Flandes, Milán, Nápoles y Cerdeña. En España, el conflicto civil había comenzado en 1705 con el desembarco del Archiduque Carlos, proclamado Carlos III, en Barcelona, pero tras la batalla de Almansa en 1707, la superioridad borbónica sólo se puso en entredicho en la crisis de 1710; la ayuda de los ejércitos de Luis XIV asentó al nuevo rey borbónico en el trono. Los acontecimientos dieron un giro radical en 1710. El triunfo de los tories en las elecciones inglesas de octubre, que representaban a una opinión pública que

8 Cardoso, J. L., Cluny, I., Dores Costa, F., y otros: O Tratado de Methuen (1703): diplomacia, guerra, política e economia, Lisboa, Livros Horizonte, 2003. Puede encontrarse un amplio estudio sobre la participación de Portugal en la guerra en Albareda Salvadó, J., León SAnz, V. (eds): Diario Bellico. La Guerra de Sucesión en España, Alicante, Publicaciones de la Universidad de Alicante, 2013.

9 BÉly, L.: Espions, et ambassadeurs au temps de Louis XIV, París, Fayard, 1990; Les relations internationales en Europe (XVIIe-XVIIIe siècles), París, 1992. 
deseaba la paz, significó que Gran Bretaña se retirase poco a poco de una larga y costosa guerra. El nuevo gobierno buscó el acercamiento a Luis XIV. La política británica se vio reforzada con la muerte de José I en abril de 1711 que convertía al Archiduque en emperador: los ingleses no iban a permitir la repetición del Imperio de Carlos $\mathrm{V}^{10}$. El acercamiento a Francia se concretó poco después en la firma de los Preliminares de Londres de 1711 que sentaban las bases de la futura paz. Inglaterra daba por finalizada la guerra.

En cuanto a su dimensión interna, el conflicto sucesorio español planteó el problema de la articulación del Estado como cuestión fundamental. Las palabras escritas por P. Fernández Albadalejo en el año 2000 siguen hoy teniendo actualidad: "enfrentado al debate sobre 'la acomodación de la diversidad' y a las expectativas abiertas por un federalismo dicho 'asimétrico', el paradigma estatalista está en cuestión'. Su crisis nos toca de cerca..." ${ }^{11}$. La contienda afectó a los distintos territorios de la Monarquía y enfrentó a las Coronas de Castilla y de Aragón. Sin duda, fue una guerra civil, pero como ha señalado recientemente J. Albareda, no se trató de una confrontación territorial, al menos inicialmente: el enfrentamiento entre los dos bloques territoriales se recrudeció a lo largo del conflicto ${ }^{12}$. Estudios recientes al analizar el desarrollo del proceso histórico en la Corona de Castilla, ponen de relieve también aquí su complejidad frente a la concepción unitaria generalmente admitida. Algunas aportaciones rebaten el mito del proyecto borbónico de la modernización del país, señalando las dificultades y la oposición a las reformas que existió en el bando felipista, con el progresivo abandono de algunos partidarios del rey francés que apoyaron su llegada al trono español. A este respecto, el conflicto dinástico propició cambios en la administración, pero la guerra obligó a recurrir a prácticas extendidas en la época de los Austrias, como la venalidad ${ }^{13}$.

Pero el mayor impulso historiográfico se ha orientado hacia el estudio de la contienda dinástica en la Corona de Aragón y particularmente en Cataluña, con especial acento en el austracismo. Se deben recordar los estudios sobre el desarrollo militar de la contienda en el Principado, o la consolidación de la Conferencia de los Tres

10 Cabe recordar el interés creciente por el debate que suscitó la política pacifista del nuevo gobierno tory en el Parlamento británico y en la opinión pública, un debate que contó con la colaboración de conocidos intelectuales como J.Swift o D.Defoe, véase a modo de ejemplo, León SAnZ, V. (ed): Daniel Defoe. Memorias de Guerra del Capitán George Carleton desde la guerra de Holanda hasta la paz de Utrecht, Universidad de Alicante, 2002 (esta edición fue la primera traducción en castellano; hay una edición catalana reciente).

11 Comentario a propósito de una cita de Fossas, E., ReQuejo, E.: Asimetría federal y Estado plurinacional, Madrid, 1999, en FERnÁNDEZ, op.cit., (nota 6), p.9.

12 Albareda Salvadó, J.: La Guerra de Sucesión de España (1700-1714), Barcelona, Crítica, 2010; Felipe V y el triunfo del absolutismo. Cataluña en un conflicto europeo (1700-1714), Barcelona, Generalitat de Catalunya, 2000.

13 Sobre las transformaciones y cambios en la administración, véanse entre otros, los trabajos de P. Molas, M.V ${ }^{\mathrm{a}}$. López-Cordón, J.P. Dedieu, MaA. Pérez Samper, G.Franco, A.Dubet, o J. Martínez Millán. Acerca del notable incremento de la venalidad, AndúJar CAstillo, F.: Necesidad y venalidad. España e Indias: 17041711, Madrid, Centro de Estudios Políticos y Constitucionales, 2008; Felices de la Fuente, Ma M.: La nueva nobleza titulada de España y América en el siglo XVIII (1701-1746), Almería, Ed. Universidad de Almería, 2012; Andújar Castillo, F., Felices de la Fuente, Ma M. (eds.): El poder del dinero. Ventas de cargos y honores en el Antiguo Régimen, Madrid, Biblioteca Nueva, 2011. 
Comunes ${ }^{14}$. Cabe señalar asimismo la importancia de los trabajos sobre la Corte austracista de Barcelona, la actuación no sólo del Archiduque, sino también de su esposa Isabel Cristina e igualmente el desarrollo y evolución de las instituciones catalanas a lo largo de la contienda, así como el papel de los grupos económicos catalanes ${ }^{15}$. La imposición borbónica de la política centralizadora a través de la Nueva Planta, acompañada de una fuerte violencia y represión, y también del exilio de muchos austracistas, dificultó que el modelo felipista se asentara en la sociedad de los antiguos territorios forales aragoneses y prolongó las consecuencias internas del conflicto ${ }^{16}$.

En estos años, los debates historiográficos han girado también en torno al análisis de otros factores que incidieron en el desarrollo de la lucha dinástica. Las actitudes de los grupos sociales en las dos Coronas, de Castilla y de Aragón, se perfilan diversas y diferenciadas, también dentro de estos territorios. La cultura política de la época se ha orientado a tratar cuestiones clave como la concepción de soberanía, la influencia del mesianismo, así como la publicística civil y religiosa y su papel relativo a la disciplina social ${ }^{17}$.

La conmemoración de la Paz de Utrecht que ponía fin al conflicto dinástico español parece un marco apropiado para hacer balance. Sin embargo, la misma complejidad de la paz impide cerrar este capítulo, no solo porque inicialmente no se sumó a la paz el emperador, habría que esperar un año para que éste firmara la Paz en Rastatt, sino porque además no hubo acuerdo entre los dos principales protagonistas, los dos candidatos a la Corona de España Felipe V y el ahora emperador Carlos VI hasta la Paz de Viena de 1725, lo que dejó abierto el conflicto entre ambas cortes y prolongó las consecuencias de la guerra de Sucesión también a nivel civil al menos hasta esta fecha.

14 Torras i Ribé, J. M.: La Guerra de Successió i els setges de Barcelona, Barcelona, 1999 (3 ed. 2007); Felip V contra Catalunya, Barcelona, 2005 (4ª ed. 2007); MArTí, E.: La Conferencia de los Tres Comunes (1697-1714). Una institución decisiva en la política catalana, Vilassar de Mar, Fundación Ernest Lluch, 2008. Sobre el desarrollo de la historiografía en el reino de Valencia, entre otros, Pérez Aparicio, C.: Canvi dinástic i Guerra de Successió. La fi del Regne de València, Valencia, 2008. Giménez, E.: Felipe v y los valencianos, Valencia, Tirant Humanidades, 2011.

15 Albareda Salvadó, J.: El “cas dels catalans”. La conducta dels aliats arran de la guerra de Succesió (1705-1742), Barcelona, 2005; LEÓn SANZ, V.: "Isabel Cristina, reina y regente en Barcelona”, en L'aposta catalana a la Guerra de Successió, (1705-1707), Barcelona, Museu d'Història de Catalunya, 2007, pp. 429440; "Jornada de Isabel Cristina a Barcelona, esposa del Archiduque Carlos, (1708)", Estudis, 33, (2007), pp. 93-114; Imatge i poder d'una reina: Elisabet Cristina de Brunsvic-Wolfenbüttel a Catalunya durant la guerra de Successió, Institut Cultura de Barcelona, Barcelona 2010.

16 El exilio de borbónicos y austracistas ha centrado en buena medida el debate historiográfico de estos años. A modo de ejemplo, véanse los trabajos de GiméNEZ, E.: "El exilio de los magistrados borbónicos de la Audiencia foral valenciana" (1707-1705)" y de LEÓN SANZ, V.: "Represión borbónica y exilio austracista al finalizar la Guerra de Sucesión española”, en ÁlvAREz-Ossorio, op.cit., (nota 6), pp. 551-566 y p. 569-589, así como de esta última historiadora, 'Abandono de patria y hacienda'. El exilio austracista valenciano", Revista de Historia Moderna. Anales de la Universidad de Alicante, 25, (2007), pp. 235-255.

17 Junto a los trabajos conocidos de M ${ }^{\mathrm{a}}$ T.Pérez Picazo, R.M A Alabrús o D.González Cruz, cabe citar, entre otros, LóPEz -CORDón, Ma V.: "Defender a un rey, convencer a Europa: razones e imágenes de la propaganda castellana durante al contienda sucesoria”, en GARcíA, op.cit., (nota 6), pp. 285-305; MuÑOZ RodríGUEZ J. D.: Felipe Vy cien mil murcianos. Movilización social y cambio político en la Corona de Castilla durante la Guerra de Sucesión (1680-1725), Murcia, Universidad de Murcia, 2010. 


\section{LA PAZ GENERAL}

Una vez se establecieron los Preliminares en 1711, Gran Bretaña y Francia iniciaron la negociación con los principales protagonistas. La reina Ana eligió Utrecht para la celebración de un congreso, pero serían las Provincias Unidas las encargadas de convocar a los contendientes a comienzos del año 1712. No todos estuvieron de acuerdo y el emperador envió al príncipe Eugenio a Londres para tratar de impedir que se celebrase el congreso o al menos se aplazara y, en todo caso, con el objetivo de anular las disposiciones franco-británicas. Ante la amenaza de una paz separada, Austria aceptó enviar plenipotenciarios a Utrecht. Quien no tuvo representación directa en el congreso durante meses, por la oposición de austriacos y holandeses, fue Felipe $\mathrm{V}$, pese a que ya en noviembre de 1711 había pensado en sus tres plenipotenciarios (Bergeyck, Osuna y Monteleón). Esta situación potenció el papel de Luis XIV como interlocutor del rey de España, y la decisiva actuación de Francia en los asuntos que atañían a la Corona española ${ }^{18}$. En principio, la discusión entre Londres, Versalles y Madrid privaba de realidad política al congreso diplomático reunido en Utrecht, sin embargo, Londres no quería una paz separada y se esforzó por incorporar a los demás contendientes.

La Paz General fue posible gracias al acuerdo franco-británico, los artífices de la paz. Eran numerosos los debates abiertos y las soluciones encontradas en muchos casos no serían definitivas, pero en todo caso, los negociadores, esta vez sí, tras los fracasos de La Haya y Gertruydemberg, lograron poner fin a una larga y costosa guerra ${ }^{19}$. En Utrecht se celebró el congreso y se firmaron importantes tratados, pero también se concluyeron tratados en otros lugares de Europa como Madrid, Rastatt o Baden, entre 1713 y 1715. Se puede sistematizar lo que conocemos como Paz de Utrecht en tres series de tratados, bien trabados entre sí: en 1713 Francia y España suscribían en Utrecht los suyos con cada uno de los aliados; el tercer bloque se firmó al año siguiente en Rastatt (1714), cuando Austria se sumó a la paz y el Imperio en Baden unos meses después. Los Tratados de Utrecht entre España y cada uno de los aliados vino a representar la aceptación de lo convenido previamente por las grandes potencias. Los acuerdos no agradaron a la mayoría de las Cortes europeas por las concesiones que tuvieron que hacer, pero esas mismas concesiones se insertan en un marco político de equilibrio, pudiéndose distinguir dos planos, entre los que forjan la

18 La relación entre Luis XIV y su nieto a través de correspondencia entre ambos monarcas centra el interés de algunas recientes investigaciones: Bernardo Ares, J. M.: Luis XIV rey de España. De los imperios plurinacionales a los estados unitarios (1665-1714), Madrid, Iustel, 2008; De Madrid a Versalles. La correspondencia bilingüe entre el Rey Sol y Felipe V durante la Guerra de Sucesión, Barcelona, Ariel, 2011. Guillamón Álvarez, F. J., Muñoz Rodríguez J. D.: La formación de un príncipe de la Ilustración. Selección de la correspondencia privada de Luis XIV a Felipe V durante la Guerra de Sucesión, CAM, 2006. BÉLY, op. cit., (nota 9).

19 La paz de Utrecht ha sido objeto de numerosos estudios. Entre los clásicos cabe recordar las obras del siglo XIX como Giraud, C.: La paix d'Utrecht, París, 1847. Los primeros contactos diplomáticos los analiza con detalle Guerrero Villar, J.: El tratado de paz con Inglaterra de 1713. Orígenes y culminación del desmembramiento de la monarquía española, Tesis doctoral. Universidad Autónoma de Madrid, 2008. Sobre los Tratados, Frey, L., Frey, M.: The Treaties of the War of the Spanish Succession, Westport, Connecticut, Greenwood Press, 1995. Remito a las referencias bibliográficas sobre la Paz de Utrecht que figuran en las colaboraciones reunidas en este volumen. 
paz y los que acceden a ella ${ }^{20}$. Los acuerdos iban a significar la desarticulación de la monarquía española en Europa en el sentido previsto en los tratados de reparto: Felipe V obtuvo España y las Indias y su rival Carlos de Austria recibió los Países Bajos españoles y los dominios italianos que habían pertenecido a la Monarquía Hispánica, a excepción de Sicilia que fue atribuida al duque de Saboya, debiéndose destacar los derechos de la Casa de Saboya a la sucesión española en caso de extinción de la rama madrileña de la Casa de Borbón ${ }^{21}$.

La historiografía coincide, por otro lado, en reconocer que la negativa de Felipe $\mathrm{V}$ a ceder en el caso de los catalanes, benefició considerablemente a Inglaterra. También es destacable que los negociadores españoles dedicaran más tiempo y esfuerzos a asegurar el ducado de Limbourg y las rentas para la Princesa de los Ursinos que a negociar la cesión de Gibraltar y Menorca. España y Gran Bretaña firmaron el 13 de julio de 1713 un Tratado de Paz y Amistad y los preliminares de un Tratado de Comercio y Navegación ${ }^{22}$. Se reconocía la soberanía británica en Gibraltar y Menorca, reservándose el rey Católico la exigencia de conservar el credo romano en ambas plazas. Junto a estas, el asiento de negros, e implícitamente el navío de permiso, fueron las principales concesiones hechas a Gran Bretaña. Recientemente, R. Fernández aporta datos que cuestionan la capacidad negociadora de los representantes españoles y muy especialmente de Felipe V, quien fue en último término el que dirigió la negociación del Tratado, si bien conviene recordar que al monarca español le quedó poco margen para introducir modificaciones y sólo debió ratificar lo previamente acordado por Francia ${ }^{23}$. El objetivo de la diplomacia de París estaba claro: cesión mínima de Francia, a costa de España; como escribía Osuna: "habiendo España cedido todo lo cedible". A este respecto, recuerda que Luis XIV había cedido en nombre de su nieto Gibraltar y Menorca, así como el asiento de negros, aunque Felipe V quiso negociar directamente con los ingleses los términos del asiento y envió al duque de Monteleón. Los diplomáticos españoles, Monteleón y Osuna, no siempre bien avenidos, se dispusieron a negociar con los ingleses en una situación de inferioridad ya que desconocían muchas cuestiones aceptadas por Luis XIV, de las que no habían sido informados. En su opinión, la negociación del Tratado del Asiento fue pésima para España, como también lo fue la renegociación de 1716.

De este modo, en el marco de la contienda dinástica española, Inglaterra iba a dar un paso fundamental hacia la hegemonía marítima y comercial, primero con la firma de los tratados de Methuen con Portugal y después con los firmados en Utrecht

20 Jover Zamora, J. Mª : Política mediterránea y política atlántica en la España de Feijoo, Oviedo, 1956; LÓPEZ-CoRdón, $\mathrm{M}^{\mathrm{a}} \mathrm{V}$.: "La construcción del equilibrio europeo. De la crisis dinástica a la regulación de la paz", MuÑoz Machado, S. y Bernardo Ares, J.M. (COORds).: El Estado-Nación en dos encrucijadas históricas Iustel, 2006, pp. 187-226; Juan Vidal, J. y Martínez Ruíz, E.: Política interior y exterior de los Borbones, Madrid, 2001.

21 Storrs, Сн.: War, Diplomacy and the Rise of Savoy, 1690-1720, Cambridge University Press, 1999.

22 Martín, M. A.: España entre Inglaterra y Francia (1711-1714), Panamá, 1964; McLachlan, J. O.: Trade and Peace with Old Spain, 1667-1750, Cambridge, 1940.

23 Véase la excelente contribución a este tema de FERnÁNDEz Durán, R.: La corona española y el tráfico de negros. Del monopolio al libre comercio, Madrid, Ecobook, 2011, p.123. También sobre Menorca, JuAN VIDAL, J.: La conquesta anglesa i la pèrdua espanyola de Menorca com a conseqüència de la guerra de Succesió a la Corona d'Espanya, Menorca, 2008; hay una edición en castellano ampliada publicada en 2013. 
con España; otros aliados, como Holanda, salieron menos beneficiados. En la Paz de Utrecht Inglaterra obtenía las ventajas a las que aspiraba desde mediados del siglo XVII en cuanto a su presencia en las Indias españolas y su participación en el negocio colonial hispano. Pero el asiento no aportó los beneficios esperados y el contrabando encubierto a través del navío de permiso provocó constantes conflictos entre ambos países durante al primera mitad del siglo XVIII. En todo caso, la guerra de Sucesión y los Tratados de Utrecht significaron en América, como ha señalado C. Martínez Shaw "refuerzo de la defensa militar, introducción de novedades administrativas, reorganización de la Carrera de Indias y expansión territorial en América, y también en el Pacífico desde Filipinas" ${ }^{24}$. En Utrecht Felipe V tuvo que renunciar al trono francés, algo que nunca admitió realmente y perdió los territorios europeos extrapeninsulares, pero mantuvo su imperio en América.

¿Qué papel jugó Austria durante las negociaciones?. Tradicionalmente la historiografía ha calificado la resistencia de la Casa de Austria como el hecho más notable en los momentos previos a la firma de la paz. Los políticos de Viena se mostraron favorables a la cesión de España a Felipe V. Pero fue el nuevo emperador, y no sus consejeros, quien iba a dirigir la diplomacia austriaca en adelante ${ }^{25}$. Carlos VI se enfrentó con los británicos cuando éstos dejaron de apoyar su presencia en España y cuando quisieron utilizar los territorios italianos como baza compensatoria de cara a una paz general, por considerarlos parte del patrimonio de la Casa de Austria, y buscó sin éxito el apoyo de otros aliados. El emperador se negó a reconocer a Felipe V como rey de España y al duque de Saboya como rey de Sicilia. En 1713 vendió el marquesado de Finale a Génova, privando de un estratégico puerto a Saboya ${ }^{26}$, al tiempo que rechazaba los consejos de sus ministros y se resistía a participar en la paz ${ }^{27}$. Tras una campaña militar indecisa entre las tropas imperiales y las francesas y, ante la dificultad financiera para continuar la guerra, durante el invierno de 1713-1714 el príncipe Eugenio de Saboya y el mariscal francés Villars iniciaron las conversaciones encaminadas a la paz en el castillo de Rastatt en Baden. El Tratado de Paz firmado en Rastatt el 7 de marzo de 1714 sería confirmado en Baden (Suiza) en septiembre seis meses después. Los tratados abordan los problemas relacionados por la tradicional rivalidad franco-habsbúrgica en el Imperio ${ }^{28}$. En lo que respecta a la herencia española, Carlos VI recibía los Países Bajos del sur aumentados con determinadas plazas, así como

24 Martínez Shaw, C.: "La guerra de Sucesión en América", en García, op.cit., (nota 6), pp. 71-93.

25 Ehalt, Ch.: La Corte di Vienna tra Sei e Settecento, Roma 1984; Kalmár, J.: “Autour de l'Empereur Charles VI: "allemands" et "espagnols" dans la cour viennoise du premier tiers du XVIII siècle", L'Etat moderne et les élites. XVIIe-XVIIIe siecles, París 1996, pp.255-256.

26 Parece que se empleó el dinero de la venta para atender las deudas contraídas durante la Guerra de Sucesión, en Castellví, F.: Narraciones históricas..., Viena, IV, 1726.

27 De acuerdo con lo que le escribió Isabel Cristina al marqués de Rialp el 29 de junio, también el Pontífice había hecho llegar al emperador que debía "hacer la paz y pensar de no perder tanta sangre. Él ha respondido que no la podía hacer de tal manera y que tampoco sabía si el rey de Francia la quería hacer”, cit. en WolfF. F.: Vierundwansig Briefe der Kaiserinn Elisabeth Gemahlinn Kaiser Karls VI an den Staats-Seretär de Rialp, Viena, 1854.

28 Wilson, P. H.: The Holy Roman Empire, 1495-1806, Macmillan Press Ltd, 1999; IngRaO, CH. W.: The Habsburg Monarchy, 1618-1815, Cambridge University Press, 1995; KLIngensteIn, G.: "Institutionelle Aspecte der Österreichischen Aussenpolitik im 18. Jahrhundert", en Zollner, E. (ed.): Diplomatie und Aussenpolitik, Wien, 1977. 
el Milanesado, Nápoles y los Presidios de Toscana. En cuanto a Cerdeña, que según acuerdos anteriores debía haber pasado al elector de Baviera, en Rastatt se decidió que fuese igualmente para Carlos VI.

El príncipe Eugenio mejoró lo que previamente se había asignado al emperador en Utrecht y fue recibido en Viena como un héroe. La paz que firmó el Imperio en Baden no era tan ventajosa, pero Carlos VI había actuado más como un Habsburgo que como emperador del Sacro Imperio, iniciando una política que le diferenciaba claramente de su padre Leopoldo I. Un año después, Viena adquiría los Países Bajos españoles tras la conclusión del tratado de la Barrera con los holandeses en Amberes el 15 de noviembre de 1715, un tratado que condicionó la viabilidad de la Compañía de Ostende en la década de los veinte. Así pues, Carlos VI obtuvo en las paces que ponían fin a la guerra de Sucesión la mayoria de los territorios europeos que habían pertenecido a la Monarquía Hispánica.

Carlos VI consiguió casi todo lo que la política imperial de Leopoldo I había pretendido en la península italiana e incluso en 1720 obtuvo Sicilia a cambio de Cerdeña ${ }^{29}$. En 1713 se entablaron conversaciones con Maximiliano II de Baviera para ofrecerle los Países Bajos españoles a cambio de la definitiva rendición de Baviera. Algunos estadistas vieneses defendían las razones estratégicas y geográficas de la unión de aquellas tierras entre Bohemia y el Tirol, pero el nuevo emperador Carlos se opuso al proyecto respetando los derechos del elector y conservando intactos los suyos en los nuevos dominios españoles que con el fin de la guerra de Sucesión se incorporaron a la Corte austriaca: "no quiso el emperador aceptarle como destructivo de sus derechos a la Monarquía de España", escribió el conde Juan Amor de Soria ${ }^{30}$.

Los dominios ganados en la guerra de Sucesión española dieron a los Habsburgo de Viena una nueva dimensión política y territorial. La desarticulación de la Monarquía Hispánica supuso un nuevo reparto de la península italiana, que encontraba su justificación en la lógica del orden europeo del equilibrio ${ }^{31}$. La hegemonía de los Austrias de Madrid, pasaba ahora a los Austrias de Viena y su nuevo dominio era interpretado en clave de continuidad. La Casa de Austria lograba imponerse a los Borbones, que quedaban fuera de Italia. Por eso, aunque en la Corte imperial algunos defendían la expansión danubiana a costa de los turcos, el nuevo emperador no podía renunciar a una parte esencial de su herencia española y base de la hegemonía de la rama principal de la Casa de Austria durante los siglos XVI y XVII y mantuvo los dos escenarios de actuación. Los austriacos podían apelar al derecho imperial para legitimar sus pretensiones sobre Milán y sus feudos, pero la situación cambiaba en los reinos de Nápoles y Sicilia: junto a la tradicional concesión de títulos, pensiones y honores para asegurarse las fidelidades, se reforzó la propaganda en relación al

29 Frey, L., Frey, M.: A question of Empire. Leopold I and the War of Spanish Succession, New York, 1983, p.67; Guía Marín, Ll.: Sardenya, una història pròxima. el regne sard a l'època moderna, Barcelona, Editorial Afers, 2012.

30 Real Academia de la Historia, (RAH), 9/5603, Amor DE Soria, J.: Addiciones y Notas Históricas desde el año 1715 hasta el 1736, Viena, 1736.

31 Galasso, G.: 'L'Italia una e diversa nel sistema degli Stati europei”, en Galasso, G., Mascilli, L.: L'Italia Moderna e l'Unitá Nazionale, Storia d'Italia, XIX, Turín 1998; Frigo, D. (ed.): Politics and Diplomacy in early Modern Italy, Cambridge University Press 2000; VERGA, M. (ed.): "Dilatar l'Imperio in Italia”. Absburgo e Italia nel primo Settecento, en Cheiron, 21 (1994). 
"mito imperial" como legitimador de la nueva presencia de la Casa de Austria. En Utrecht-Rastatt, como se ha señalado, la mayor parte de los territorios italianos de la monarquía pasaron a la Corte de Viena, a excepción de Sicilia que recibió el duque de Saboya, nuevo aliado británico que mantenía el equilibrio en la península italiana reduciendo el poder de los austriacos. Felipe $V$ se opuso con insistencia a la cesión de Sicilia, único territorio italiano que no había caído en manos de los aliados. En cuanto a Cerdeña, su paso primero a Viena y después a Saboya significó el acercamiento a la órbita italiana y el distanciamiento de la monarquía hispánica y en particular de la Corona de Aragón a la que había pertenecido durante siglos. En este juego de intereses y tras el abandono británico y portugués del conflicto peninsular, el Principado de Cataluña perdió interés también para la Corte de Viena.

Ciertamente, la paz de Utrecht privó a Carlos VI de la parte más importante de su herencia española, pero garantizó la posesión de los territorios italianos y flamencos de España ${ }^{32}$. A finales de 1713 y antes de la firma de la Paz de Rastatt se constituyó en Viena el Consejo Supremo de España, que establecía una intencionada continuidad institucional con el sistema político de la Monarquía Hispánica, pero además legitimaba el papel "hereditario" de Carlos VI y garantizaba el consenso en los Estados italianos como habían hecho los Austrias españoles en los siglos anteriores, con la vuelta al respeto de las competencias y de la representación política de las perife$\operatorname{rias}^{33}$. El establecimiento del Consejo de España vino a simbolizar el rechazo de la Corte austriaca a reconocer a Felipe V como rey, pero junto a su finalidad reivindicativa, también iba a cumplir otro objetivo no menos importante para el gobierno de los nuevos territorios, la aceptación del nuevo dominio austriaco.

Aunque en la Paz de Rastatt Carlos VI no había renunciado a la Corona de España, en última instancia, la paz separada con Francia dejó a Felipe V la solución final del problema catalán, aunque la noticia de la paz entre el emperador y Luis XIV dio renovadas esperanzas a los asediados catalanes. Después de catorce meses de sitio y una fuerte resistencia, la ciudad capituló el 11 de septiembre de 1714. La reina Ana Estuardo fallecía el 12 de agosto de 1714 y le sucedía Jorge I de Hannover. También en ese mismo año los whigs volvían al poder, lo que unido a una actitud favorable del nuevo rey Jorge I, animó a los catalanes a reclamar de nuevo el apoyo británico, pero sólo obtuvieron buenas palabras. A pesar de que Jorge I, con intereses continentales,

32 León Sanz, V.: Carlos VI. El emperador que no pudo ser rey de España, Madrid, Aguilar, 2003; "El partido español en la Corte imperial de Carlos VI: La Conferencia de Estado.”, en Martínez Millán, J. y González Cuerva, R. (coords.): La Dinastía de los Austria. Las relaciones entre la Monarquía Católica y el Imperio. Colección "La Corte en Europa" Temas, Editorial Polifemo, 2011, III, p.1663-1688. AuER, L.: "Österreichische und europäische Politik um das Spanische Erbe", Archiv und Forschung, 20, 1993; CREMONINI, C.: Traiettorie politiche e interessi dinastici tra Francia, Impero e Spagna: il caso di Carlo Enrico di Lorena, principe di Vaudémont (1649-1723), Milano, 2008. Una interpretación actualizada sobre el significado del gobierno austriaco en Italia puede encontrarse en GuASTI, op.cit., (nota 6). Sobre Flandes, VAN GELDER, K.: 'Divided Loyalties'. Angevin Partisans in the Southern Netherlands in the Aftermath of the War of the Spanish Succession', Dutch Crossing, 34-1(2010), pp. 59-76; 'L'empereur Charles VI et '1'héritage anjouin' dans les Pays-Bas méridionaux (1716-1725), Revue d'histoire moderne et contemporaine (2011).

33 Galla, F.: "Italia entre los Habsburgo y los Borbones", en Fernández, op.cit., (nota 6), pp. 141-162; Álvarez-Ossorio, A.: "Restablecer el sistema: Carlos VI y el estado de Milán (1716-1720), Archivio Storico Lombardo, Anno CXXI-1995, p.177 y ss; Cremonini, C.: Alla Corte del Gobernatora. Feste, riti e ceremoniae a Milano tra XVI e XVIII secano, Milano, Bulzoni Editore, 2012. 
y los whigs se manifestaron contrarios a la política de los tories en Utrecht, respetaron los acuerdos de 1713.

\section{LA MONARQUÍA DE ESPAÑA Y LOS TRATADOS DE UTRECHT}

Después de estos años de intensa producción historiográfica y de avances significativos en el conocimiento del conflicto dinástico español, en su doble vertiente, de guerra internacional y de conflicto civil, se ha considerado pertinente enfocar este número a las negociaciones que condujeron a la Paz de Utrecht, sin olvidar las dinámicas políticas previas y propias del escenario europeo e hispano, prescindiendo deliberadamente de aspectos y temáticas a las que se ha prestado mayor atención y en los que la problemática interna, al menos en buena parte de la historiografía española, ha tenido un peso mayor. Las aportaciones se han centrado en la etapa final de la guerra, y se ha puesto el foco en temas centrales de este período, como las negociaciones de Utrecht o la guerra en Cataluña. También se han incluido escenarios menos habituales que aportan diferentes perspectivas como Cerdeña, la suerte de los territorios italianos de la monarquía de España o las relaciones hispano-lusas en la primera mitad del siglo XVIII, de interés creciente en la historiografía española, a través de la cesión de la Colonia de Sacramento, atendiendo también así a la dimensión americana de Utrecht, y al mundo colonial y el comercio ultramarino.

Al hilo de la reflexión suscitada de la lectura de las aportaciones, este número se ha estructurado en dos grandes apartados. Se ha atendido en primer lugar a las relaciones de España con Francia e Inglaterra, y también con Portugal. Felipe V debió aceptar en buena medida lo acordado previamente por los negociadores franceses y británicos en Europa y en América, en cuestiones dinásticas, territoriales y comerciales. Un segundo apartado incluye los estudios relativos a la posición de la Corte de Viena a través del análisis de los dos principales escenarios en litigio en la etapa final del conflicto y presente en el tablero de las negociaciones: el Principado de Cataluña y la península italiana. Cerdeña, una isla de la Corona de Aragón, con frecuencia olvidada, tiene aquí también su espacio.

Los estudios ofrecen, pues, desde diferentes ángulos una visión preferentemente política y vinculada, aunque no de manera exclusiva, a la historia renovada de la diplomacia y de las relaciones internacionales, en la que los agentes políticos y sociales, o los factores económicos juegan un papel determinante, sin olvidar los planteamientos realizados en el marco de la historia social y de la historia militar. No se ha pretendido una visión unitaria ni en los temas ni en las perspectivas y tampoco ha sido objetivo ofrecer un estudio exhaustivo de los Tratados, lo que hubiera sido cuando menos pretencioso, y giran en torno a cuestiones relativas a los dos rivales a la sucesión de Carlos II y los dominios de la Monarquía Hispánica en Europa y América. Las aportaciones realizadas en torno a la nueva Europa de Utrecht ofrecen el enfoque original de sus autores, pertenecientes a diferentes historiografías europeas.

Las dos monarquías borbónicas, la española y la francesa, aparecen unidas por estrechos lazos, familiares y políticos, durante la guerra de Sucesión. Los dos primeros estudios tienen como objeto analizar la relación entre las Cortes de Versalles y 
Madrid desde la particular mirada de la relación del monarca francés con su nieto. El difícil diálogo entre las dos monarquías borbónicas se centró a partir de 1712 en el intento de Luis XIV de imponer a su nieto los acuerdos de la diplomacia francesa con Inglaterra y Holanda. Especialista reconocido de la guerra de Sucesión, J. Albareda nos ofrece un sugerente e interesante trabajo en el que, a través de la relación de $\mathrm{Fe}$ lipe $\mathrm{V}$ con su abuelo, no exenta de tensiones, profundiza en un tema tradicionalmente aceptado por la historiografía relativo al papel desempeñado por Luis XIV en representación de los intereses de España en el transcurso de las conversaciones con los aliados conducentes a la Paz. Su análisis de las instrucciones dadas por Felipe V durante la negociación resulta esclarecedor sobre el cambio de actitud del monarca español, quien tuvo que abandonar los planteamientos idealistas iniciales y adoptar una posición realista en vísperas de la celebración del congreso de Utrecht. La correspondencia de Felipe V con Luis XIV, las mismas instrucciones de aquel, o el testimonio de otros protagonistas, permiten al autor mostrar la complejidad de las negociaciones dirigidas por la Corte francesa y clarificar la, en ocasiones, difícil relación entre los dos monarcas, entre abuelo y nieto, poniendo de manifiesto "las ambiciones y las frustraciones de Felipe V, supeditado en último término a los dictados de Luis XIV".

En tiempos recientes la historiografía europea está reevaluando el análisis de la dimensión europea y colonial de la guerra de Sucesión española. El trabajo de Lucien Bély se sitúa en el marco de lo que podríamos llamar la historia de la diplomacia en la que el autor es un maestro reconocido. Con una atención preferente a los intereses de la diplomacia de París, se centra en buena parte en los aspectos económicos y en particular en la cuestión del comercio americano, especialmente el interés francés, superando así la perspectiva europea dominante. Explica las distintas fases por las que atraviesa el comercio franco-español primero y anglo-español después durante la guerra de Sucesión, debiéndose destacar su estudio sobre la mediación económica y diplomática de Nicolás de Mesnager. También merece señalarse la utilización, entre las fuentes impresas, del informe sobre Nueva España de Jean de Monségur. Asimismo, se explican las distintas posiciones de Luis XIV y de Felipe $\mathrm{V}$ en relación con la complicada cuestión dinástica, tras las muertes acaecidas en la Casa Real francesa. Se trata de un tema central de las negociaciones de Utrecht que el autor expone en el marco de las relaciones hispano-francesas: la cuestión dinástica de aceptación o renuncia a la Corona de Francia por Felipe V, analizando las complejas relaciones entre Versalles y Madrid desde una perspectiva diplomática. Una renuncia de imposición inglesa de una "racionalidad política" frente al derecho divino de los reyes.

La muerte del Delfín abrió un nuevo frente en las negociaciones. Con el camino allanado por Francia, Inglaterra inició contactos directos con la Corte borbónica española. Londres envió entonces a Madrid a Lord Lexington. El historiador británico Christopher Storrs ofrece una detallada reconstrucción de la misión diplomática, no bien conocida, de Lexington en Madrid, en un momento de gran importancia para los intereses británicos, entre 1712 y 1713, los meses previos y posteriores al Tratado de Paz entre España y Gran Bretaña. En su análisis ofrece los rasgos de la personalidad del enviado e identifica las cuestiones en las que intervino, con indicación del margen de actuación que alcanzó en cada una de ellas. Su objetivo principal fue lograr la renuncia de Felipe V al trono de Francia. Una vez resuelta esta cuestión, aún perma- 
neció seis meses, en los que apoyó el Tratado de Comercio hispano-británico, que incluía la negociación del asiento de negros, así como la cesión de Gibraltar y Menorca. La misión se estudia en el marco de la situación política y diplomática del momento, con atención a los objetivos generales del gobierno de la reina Ana y de sus aliados, como la cesión de Sicilia al duque de Saboya y la Colonia de Sacramento a Portugal. Tras resolver la cuestión de la renuncia, el caso de los catalanes emergió a un primer plano, pero la Corte española, explica Storrs, no parecía muy inclinada a escuchar a los representantes del gobierno británico con relación a este tema.

El equilibrio de Utrecht también tuvo su dimensión americana. Si el tratado francobritánico afectó sobre todo a América del Norte, los imperios ibéricos no quedaron al margen. La firma del tratado hispano-portugués se retrasó hasta 1715. En la etapa final de la guerra se abrió un debate en la Corte lusitana relativo a si el país debía llegar a la paz solo o de la mano de Inglaterra. Entre las órdenes que recibió Lexington de Londres, se incluyó el apoyo británico a la pretensión portuguesa de la Colonia de Sacramento. Por la paz de Utrecht, la Corona portuguesa consiguió este territorio que tanto anhelaba en América, la Colonia de Sacramento, y una compensación de España por la pérdida del asiento de 600.000 escudos. Se trataba de dos concesiones que sólo la insistencia británica había hecho posibles. La Corte de los Braganza se decantó por una continuada política de neutralidad tutelada por Inglaterra, ya que parecía poder garantizar la defensa de Brasil y de las rutas atlánticas, objetivos prioritarios de Lisboa a partir de ahora. José Damiao Rodrigues aborda las negociaciones entre España y Portugal en torno a la Colonia de Sacramento. Se trata de un asunto de conocida importancia en las relaciones entre las dos Coronas ibéricas, caracterizado por las tensiones provocadas por la colonización portuguesa de la margen izquierda del Río de la Plata durante buena parte de la Edad Moderna. A este respecto, en el trabajo se estudian los estratégicos movimientos de población promovidos por la Corte de Lisboa desde las islas de las Azores y Trás- os-Montes entre 1715 y 1750, fechas de los Tratados de Utrecht y de Madrid. Se trata de un escenario y una problemática menos habitual en la historiografía española, pero de interés para encuadrar mejor las relaciones hispano-lusas en el siglo XVIII. La nueva Colonia de Sacramento se convirtió en el punto más meridional del dominio portugués en América.

Junto a Felipe V, el otro protagonista, el rival al trono de España, el Archiduque Carlos, que desde 1711 era emperador Carlos VI. El nuevo emperador afrontó las negociaciones de Utrecht desde una aparente posición de fuerza consciente de su nueva situación. Sin embargo, la Casa de Austria parece guiarse en la etapa final de la guerra por intereses contradictorios. Por un lado, Carlos VI deseaba conservar Cataluña, por su compromiso con los catalanes y por mantener un pie en la península, pero poco a poco se impuso el realismo y los esfuerzos de la Corte austriaca se dirigieron a la defensa de los territorios de la Monarquía Hispánica en Italia, dejando a su suerte al Principado, aunque no se reconociera abiertamente. Como un tablero de ajedrez, la Casa de Austria jugó sus bazas en la "firme" defensa de ambos escenarios durante las negociaciones. La posición imperial es analizada por János Kálmar, buen conocedor de la Corte de los Habsburgo de Viena en la transición del siglo XVII al XVIII. Centrado en la Corte austriaca, el historiador húngaro parte de las negociaciones que se iniciaron en 1712, a las que se opuso sistemáticamente el emperador Carlos VI, a 
través de su plenipotenciario el conde de Sinzendorf, exigiendo la totalidad de la herencia de la Monarquía Hispánica. Una vez contextualizada la posición de la Corte de Viena ante las negociaciones de Utrecht, se centra en un original proyecto diseñado por Carlos VI, consistente en enviar a su hermana mayor, la archiduquesa María Isabel, como gobernadora de Cataluña en sustitución de su esposa, la emperatriz Isabel Cristina, que habría de regresar a Viena en 1712; el viaje, que se debía de llevar a cabo entre julio y septiembre de ese año, se preparó con todo detalle. El estudio de la propuesta incluye el análisis del entorno cortesano de la archiduquesa en Barcelona, en cuya organización y etiqueta colaboró el que estaba designado para ser su mayordomo, Johann W. Gallas. Carlos VI proponía enviar a Cataluña como gobernadora a un miembro de su familia, siguiendo una práctica habitual en la época de Carlos V y Felipe II, referentes del nuevo emperador.

Las negociaciones de Utrecht tuvieron una incidencia inmediata en los diferentes frentes europeos, pero muy especialmente en Cataluña, donde la percepción de la guerra había cambiado radicalmente tras el fracaso de la ofensiva aliada sobre Madrid. Gran especialista del desarrollo de la contienda dinástica en el Principado, Josep $\mathrm{M}^{\mathrm{a}}$ Torras i Ribé plantea con su habitual agudeza en un sugerente artículo la repercusión de las negociaciones de Utrecht en el Principado. Las noticias y rumores sobre los acuerdos alcanzados en Utrecht llegaban por medio de gacetas y comunicaciones diplomáticas, a lo que se unían los informes recogidos sobre el terreno por los agentes de la Generalitat. Los frentes de batalla de Cataluña atravesaron diversas etapas, pero la iniciativa militar pasó de manera definitiva a los ejércitos de las dos coronas; a partir de la primavera de 1711 se afianza su presencia militar en toda la geografía catalana, al tiempo que se infiltraban espías y agentes borbónicos. Salvo algunas operaciones de cierta envergadura destinadas a consolidar posiciones en el nuevo mapa estratégico de la contienda, como el intento de recuperar Girona, el autor califica la incierta situación de virtual armisticio. Si la defección británica causó malestar, la sospechosa actitud adoptada por las autoridades imperiales pone de manifiesto, explica este historiador, hasta qué punto estaban comprometidas en el cumplimiento de los acuerdos que se estaban negociando en Utrecht, a pesar de no haber participado directamente en su gestación. El desaliento de la sociedad catalana fue en aumento por el desarrollo de la guerra y las noticias que llegaban de las cortes europeas, desde la salida del Archiduque en septiembre de $1711 \mathrm{y}$ de su esposa Isabel Cristina, que se había quedado en Barcelona como Reina Gobernadora, en marzo de 1713, hasta la marcha del nuevo virrey Stahremberg tras la firma del Convenio de Hospitalet que concretaba el Tratado de Evacuación de las tropas imperiales en junio de ese año. Particularmente interesante resulta su interpretación sobre lo que califica de doble juego de Stahremberg en vísperas de la firma del Convenio de Hospitalet: aseguraba la quietud de los catalanes mientras organizaba discretamente la evacuación de las tropas imperiales. A este respecto, analiza la dimensión sesgada y propagandística del conflicto sucesorio que, en su opinión, tuvo su máxima expresión en la persistente política de desinformación y ocultamiento puesta en práctica por el mariscal.

A través de la figura del cardenal Benet Sala, Rosa $\mathrm{M}^{\mathrm{a}}$ Alabrús analiza la posición del clero, y en particular del clero catalán durante la contienda sucesoria demostrando, más allá de tópicos, la actitud no siempre definida de este estamento, también 
en Cataluña. El cardenal Sala o el arzobispo de Valencia Folch de Cardona son dos buenos ejemplos indicativos del posicionamiento discontinuo especialmente de la jerarquía eclesiástica a lo largo de la guerra, así como el carácter plural de sus expresiones políticas, en las que la cuestión regalista o la promoción personal tuvieron un papel fundamental. El estudio se contextualiza en el análisis de las relaciones entre el poder político, la Santa Sede y la estructura eclesiástica española durante la guerra de Sucesión. El caso de Benet Sala muestra que las posiciones del clero catalán nunca fueron rígidas. El cambio de bando o la ambigüedad fueron frecuentes. Personaje incómodo en las postrimerías de la guerra para las Cortes de Madrid, Viena y Roma, terminó sus días poco después de llegar a la Ciudad Eterna, una vez firmada la Paz de Utrecht. La biografía de este personaje del alto clero catalán aparece expresiva de las vicisitudes que vivieron los clérigos en el exilio durante el conflicto dinástico. No escapa a la atención de esta historiadora la utilización de la religión en los dos bandos, lo que convirtió la guerra de Sucesión en un conflicto religioso. El trabajo se basa en fuentes de la publicística que la autora conoce bien, junto a la documentación del Archivio Segreto Vaticano, lo que otorga a este estudio un original enfoque.

La península italiana fue un escenario privilegiado de la disputa dinástica entre Austrias y Borbones. No hay que olvidar que la guerra comenzó por la resolución de la Corte del emperador Leopoldo I de invadir Italia en 1701 con el fin de mantenerla bajo el control de la Casa de Austria. Cinzia Cremonini afronta, desde los nuevos enfoques de la historia política, la dimensión italiana de la guerra de Sucesión y las diferentes estrategias de los territorios italianos con relación a los dos candidatos a la sucesión y sus consecuencias en el periodo inmediatamente posterior. Profundiza en la relación de estos territorios, en particular los pertenecientes a la monarquía de España, con las Cortes de Viena, Barcelona y Madrid, y se centra en el papel de los agentes políticos, las redes de poder y las estrategias en el proceso de toma de decisiones. El paso de Nápoles y Milán a Viena fue complejo. La historiadora italiana apunta los elementos de continuidad y de cambio. La formación del Consejo de España tuvo una repercusión inmediata en los dominios italianos. Se impuso una nueva dialéctica político-institucional entre la Corte imperial y las magistraturas locales, ya que si bien se movían en defensa de sus privilegios y de las tradicionales prerrogativas de las clases principales, éstas se insertaron poco a poco en la política imperial. Los españoles aparecían ante los italianos como la prolongación de un régimen ya existente y limitaba las consecuencias derivadas del establecimiento de un nuevo gobierno con el cambio de Madrid por Viena. En Utrecht, Italia quedó sacrificada a la nueva ordenación territorial, pero el reparto, como recuerda esta historiadora, fue "inestable", lo que se comprobó en los años siguientes, y tuvo un primer reajuste en 1720, por el Tratado de La Haya.

Precisamente este reajuste afectó a Cerdeña. Lluís Guia, un gran conocedor de la historia sarda en la primera mitad del siglo XVIII, realiza un interesante estudio sobre los cambios de soberanía sufridos por la isla en las negociaciones de Utrecht a Rastatt y en los reajustes posteriores. La situación de olvido historiográfico referido a los primeros decenios del siglo XVIII, atribuible por razones diferentes a la historiografía italiana y a la española, se ha empezado a superar gracias, entre otros, a los estudios del propio autor. Tras la conquista austriaca de Nápoles y Milán durante la guerra, 
Cerdeña adquirió una importancia estratégica renovada. La sombra imperial mantuvo la isla a salvo en Utrecht. Del gobierno de Barcelona pasó a depender del nuevo gobierno de Viena sin grandes sobresaltos, pasando a depender primero del Consejo de Aragón austracista y después del Consejo de España que se establece en Viena. La recomposición de las élites, explica, será relativamente rápida después de la contienda dinástica. Los referentes territoriales y políticos del reino sardo fueron a partir de entonces sobre todo Milán o Nápoles, lo que supuso la ampliación de sus lazos con el espacio italiano, en sustitución de aquellos que durante siglos había mantenido con los territorios ibéricos. No durará mucho esta situación porque Cerdeña será de nuevo moneda de cambio en los reajustes del equilibrio que provocó la política revisionista de Felipe V, lo que en opinión del autor precipitó un destino anunciado: Cerdeña pasaba en 1720 a los Saboya, y eso implicará su integración definitiva en el espacio italiano. Pero esos cambios se llevaron a cabo en el particular marco de Utrecht. El futuro de Cerdeña aparece en parte unido al de Sicilia, puesto que las condiciones de cesión de dicha isla contemplaban una serie de cláusulas que aseguraban la conservación de sus derechos y privilegios, teniendo a las potencias europeas como garantes. De este modo, Cerdeña fue el único territorio de la Corona de Aragón que conservó gran parte de su contexto jurídico e institucional hasta finales del siglo XVIII.

Los Tratados de la Paz de Utrecht que pusieron fin a la guerra de Sucesión española impusieron una gran reorganización geopolítica en Europa. Utrecht inauguró una nueva etapa en las relaciones internacionales que se asentaba sobre un "equilibrio razonable y búsqueda de la paz perpetua", una propuesta diseñada por Gran Bretaña, considerada tradicionalmente como la gran triunfadora, con la consecución de sus objetivos comerciales y ultramarinos. El fundamento del equilibrio continental, balance of power, se completa con el establecimiento de barreras y el control de las rutas marítimas, instrumentos necesarios para asegurar el sistema. La nueva ordenación europea se completó con las paces de Nystadt (1721) y Passarovitz (1718) que pusieron fin a los conflictos en el Norte y en el Este de Europa. La aplicación de la doctrina del equilibrio no evitó las contiendas en Europa y nuevas guerras tuvieron un origen dinástico, aunque emergieron con fuerza las motivaciones comerciales y coloniales. Diversos factores, vinculados a la guerra de Sucesión y a su resultado, determinaron el interés prioritario de Felipe $\mathrm{V}$ por el escenario italiano después de Utre$\mathrm{cht}^{34}$. El conflicto italiano implicó a otras potencias occidentales, como Inglaterra, Francia, Holanda o Saboya. La diplomacia de Felipe V durante su reinado sólo puede explicarse a partir de las duras condiciones impuestas en los Tratados de Utrecht en Europa y en América y la permanente voluntad regia de revisar sus cláusulas. Por otro lado, la nueva Europa marginó el problema catalán y la dimensión interna del conflicto dinástico español, al que en principio pondría fin la Paz de Viena de 1725.

Los estudios recogidos en este volumen incluyen las negociaciones de los tratados, y, en menor medida, también analizan sus consecuencias, lo que permite ponderar los

\footnotetext{
34 "España fue la principal responsable de las crisis que tuvieron a Europa en suspenso en los quince años siguientes a los tratados de Utrecht", en Zeller, G.: Los tiempos modernos, en Renouvin, P. (dir.): Historia de las relaciones internacionales, I, Madrid, 1960, p. 654. Sobre el significado de los Tratados, Jover ZAMORA, J.M. y Hernández SAndoica, E.: "España y los Tratados de Utrecht" en La época de los primeros Borbones, I, en Historia de España de Menéndez Pidal, vol. XXIX, Madrid, 1985, pp. 341-440.
} 
límites de la paz. Concluyo estas líneas no sin antes agradecer la generosa respuesta y las valiosas aportaciones, pese a sus numerosos compromisos, de los autores que colaboraran en este número. Participan en él, como hemos visto, historiadores de origen francés, inglés, italiano, portugués y húngaro, además de español, lo que explica los diferentes idiomas en los que se ha publicado. Se trata de una apuesta arriesgada, sugerida y promovida desde diversas instituciones. Asimismo, deseo agradecer al Consejo de Redacción de la Revista Cuadernos de Historia Moderna la oportunidad de haber facilitado que este volumen monográfico de Anejos del año 2013 tuviera como destino repensar Utrecht. Mi agradecimiento también a los expertos que han colaborado con sus evaluaciones, y cuyas apreciaciones han mejorado su resultado. Por último, deseo agradecer la inestimable y eficaz colaboración en el proceso de edición del joven historiador Julio López Arteaga así como a Bernardo García y a Ana Moreno Meyer. La guerra de Sucesión española que estalló en 1701, ha escrito L. Bély, obedecía a una lógica europea antigua, "fue un conflicto que comprometió el destino de Casas Soberanas que encarnaban pueblos y Estados"; en cambio, "la paz de Utrecht se construyó sobre principios muy distintos que tenían en cuenta los entramados internacionales y las relaciones de fuerza entre las potencias. Se trataba de una lógica nueva, en la que tras los príncipes aparecían los pueblos, los Estados y a veces incluso las naciones" ${ }^{\prime 35}$. Una nueva Europa surgía en Utrecht.

35 Bély, L.: "Casas soberanas y orden político en la Europa de la Paz de Utrecht", en Fernández: op.cit. (nota 6), p.67-95; L'art de la paix en Europe. Naissance de la diplomatie moderne, XVIe-XVIIIe siècle, Paris, PUF, 2007. 